\title{
Mechanical behaviour of poly(lactic acid)/cellulose nanocrystal nanocomposites: A comparative study between conventional tensile test and small punch test
}

\author{
S. Singh ${ }^{1,2}$, O. Santana-Pérez ${ }^{1}$, C. Rodriguez ${ }^{3}$, K. Oksman ${ }^{2}$, M. Ll. Maspoch ${ }^{1}$ \\ ${ }^{1}$ Centre Català del Plàstic (CCP)-Universitat Politècnica de Catalunya Barcelona Tech (EEBE-UPC)-ePLASCOM. Avda. \\ Eduard Maristany, 14. 08019 Barcelona, Spain \\ ${ }^{2}$ Luleå University of Technology (LTU), SE 97187 Luleå, Sweden \\ ${ }^{3}$ IUTA, Universidad de Oviedo, Edificio Departamental Oeste, N-7, 33203 Gijón, Spain
}

Received 25 February 2020; accepted in revised form 25 May 2020

\begin{abstract}
The use of nanocomposites is increasingly frequent as a way to improve the mechanical behaviour of polymers. In the specific case of poly(lactic acid) (PLA), the use of cellulose nanocrystals (CNC) as a reinforcing material is an interesting option, once the tendency of CNCs to agglomerate has been solved. One of the possible solutions to this problem is a superficial modification of CNC's nanocrystals through a ring-opening polymerization (ROP) process. This work analyzes the use of $\mathrm{CNC}$ nanocrystals modified using ROP $(\mathrm{mCNC})$ as a reinforcement of PLA. The mechanical properties of PLA/CNC nanocomposites are evaluated using tensile tests and small punch tests (SPT) on films prepared by extrusion calendering and post processed by compression molding. The addition of non-modified CNC promotes multiple crazing in PLA, increasing its ductility. mCNC leads to a more dispersed nanocomposite, a slight increase in the elastic modulus and a drastic decrease of crazing in tensile tests. The same tendency has been observed with SPT, and the applicability of this test in the prediction of the tensile modulus $(E)$ of polymeric nanocomposites has been demonstrated. However, more work is needed to find the ideal SPT parameter to estimate the yield point.
\end{abstract}

Keywords: biopolymers, biocomposites, material testing, poly(lactic acid) (PLA), cellulose nanocrystals (CNC), small punch test (SPT)

\section{Introduction}

Poly(lactic acid) (PLA) is a bio-based polymer which has gained much attention from the research community due to its potential to substitute some oilbased polymers. It has been used in medical applications for many decades, but in recent years its application in packaging field is being explored. Its mechanical properties are similar to polystyrene (PS) and comparable to poly(ethylene terephthalate) (PET). However, it has some drawbacks such as a slow crystallization rate, low maximum temperature for use, poor barrier properties and brittleness which restrict its use in packaging applications $[1,2]$.
One way to reduce these drawbacks is by the addition of nanofillers. Naturally available reinforcing agents such as cellulose nanocrystals (CNC) are highly promising materials due to their availability, biodegradability, high aspect ratio and good mechanical properties [3]. $\mathrm{CNC}$ has been used as a reinforcing agent in polymers such as polypropylene (PP) [4] and polyvinyl alcohol (PVA) [5]. In the case of PLA, CNC has shown effectiveness as a second stage nucleating agent (during the cold crystallization process), increasing crystallinity and consequently the mechanical properties in the rubbery state (post$T_{\mathrm{g}}$ ), after undergoing a process of annealing at $80^{\circ} \mathrm{C}$ 
for 3 days [6]. Similar results could be inferred from the work of Yu et al. [7].

However, the dispersion and distribution of $\mathrm{CNC}$ in PLA is challenging during processing as it has a tendency to agglomerate due to its hydrophilic character as opposed to the hydrophobic nature of PLA [3]. To overcome this difficulty, efforts have been made to modify the surface of CNC using different methods [8]. One way is to graft reactive or compatible groups with PLA, on the CNC surface. In this work, the surface of CNC was modified by grafting PLA using ring-opening polymerization (ROP) [9]. This modification has a double function: it improves the dispersion and distribution of $\mathrm{CNC}$, while increasing its compatibility with PLA.

One way to evaluate this compatibility is through mechanical tests. However, as in any research stage of new nanocomposites, the amount of material available can be very small, making the use of miniature tests necessary for their mechanical characterization. Among these, the small punch test (SPT) has been widely used for many years to test mechanical properties, especially those of metallic materials. Recently, researchers have started exploring its potential to test polymeric materials as well. For example, Gidding et al. [10] applied the technique to UHMWPE, HDPE, PTFE, polyacetal and poly(methyl methacrylate) (PMMA) bone cement. Jaekel et al. [11] in PEEK. Rodriguez et al. [12] successfully employed SPT for testing the mechanical properties of different polymers: EVOH, PP, PET, PETg and PLA sheets. The SPT was also used to characterize PLA reinforced with organically modified nanoclay (o-MMT) films $[13,14]$.

The small punch test can be briefly described as follows. A thin specimen is clamped between two circular dies and stretched to failure point with a hemispherical head punch at a constant displacement rate. A load cell located above the head punch measures the reaction force of the sample to the punch displacement, while the actual specimen displacement is recorded using clip-gage knife-edge extensometers. From the obtained load-punch displacement, curves are analyzed, and several parameters to identify each deformation region (elastic, plastic and failure) are obtained.

From the load-punch displacement curves, the initial slope of the curve, Slope $e_{\text {ini, }}$, as a measure of the elastic modulus, and the load at the first maximum, $P_{\mathrm{y}}$, usually related to the yield strength $\left(\sigma_{\mathrm{y}}\right)$, according to the Equations (1) and (2) with parameters obtained from tensile tests in the case of polymeric materials:

$$
\begin{aligned}
& E=\alpha_{1} \frac{\text { Slope }_{\mathrm{ini}}}{t}+\alpha_{2} \\
& \sigma_{\mathrm{y}}=\beta \frac{P_{\mathrm{y}}}{t^{2}}
\end{aligned}
$$

where $t$ is the initial specimen thickness and $\alpha_{1}, \alpha_{2}$ and $\beta$ are characteristic material coefficients when the same devices, sample geometries and testing conditions are used [12]. Thus, a pre-requisite for using this test technique is to know the values of these coefficients a priori.

Rodríguez et al. [12], working with several polymeric systems, determined the values of these characteristic coefficients using a linear fit of the correlation between the SPT parameter tests and their respective $E$ and $\sigma$ obtained from tensile tests. From the global adjustment, the values obtained were $12.439,1426.3$ and 0.0971 for $\alpha_{1}, \alpha_{2}$ and $\beta$, respectively.

The main aim of this work is to evaluate the effect of the addition of a surface-modified CNC compared with unmodified one, on mechanical properties of PLA to determine its viability as a sustainable biocomposite for packaging applications. In this paper, a correlation between tensile test and small punch test (SPT) technique will be evaluated, taking into consideration the different loading modes that each of them applies. In addition, a correlation with the deformation micromechanisms involved in each loading mode is carried out.

\section{Experimental section}

\subsection{Materials}

Poly(lactic acid) (PLA) (4032D grade) was purchased from Nature Works (Nebraska, USA). The ratio of 1-lactic acid and D-lactic acid in PLA was 98.6/1.4. The number average $\left(M_{\mathrm{n}}\right)$ and weight average molecular weight $\left(M_{\mathrm{w}}\right)$ of the PLA were 90 and $181 \mathrm{~kg} \cdot \mathrm{mol}^{-1}$, respectively [15]. Cellulose nanocrystals (CNC) (2013-FPL-CNC-049) were kindly provided by Forest Products Laboratory (FPL), (Madison, USA). A needle-like structure was observed for CNC. The width and length of the CNC lied in the range of 3-11 and $161-550 \mathrm{~nm}$, respectively. L-lactide, stannous octoate $\left(\mathrm{Sn}(\mathrm{Oct})_{2}\right)$, toluene, dichloromethane, chloroform and $N, N$-dimethylformamide (DMF) were purchased from Sigma Aldrich (St. Louis, USA). Methanol, ethanol, 1,4-dioxane, 
and acetone were supplied by VWR International (Leuven, Belgium). All the chemicals and solvents were ACS grade.

\subsection{Surface modification of $\mathrm{CNC}$ using ring opening polymerization (ROP)}

To get better dispersion of CNC in PLA matrix, the surface of CNC was modified. PLA chains were grafted on the surface of CNC by ROP of L-lactide. The procedure for surface modification as followed by Mujica-Garcia et al. [9] was used. In short, the aqueous suspension of $\mathrm{CNC}$ was solvent exchanged with acetone, dichloromethane and finally with dry toluene using centrifugation and re-dispersion cycles. L-lactide was dissolved in dry toluene in a three-neck round bottom flask connected to the condenser. After that, previously dispersed $\mathrm{CNC}$ was poured into the reaction flask, heated to $80^{\circ} \mathrm{C}$ and stirred using a magnetic stirrer at $150 \mathrm{rpm} .0 .2 \mathrm{~g}$ of $\mathrm{Sn}(\mathrm{Oct})_{2}$ was added as a catalyst into the reaction flask dropwise using a syringe and the reaction was kept for $24 \mathrm{~h}$. The product was recovered in toluene followed by redispersion cycles to remove the unreacted monomers using methanol, ethanol, and acetone. The grafting of CNC is illustrated in Figure 1. The effectiveness of this treatment was verified by FTIR as by Mujica-Garcia et al. [9]. In mCNC FTIR spectrum was observed the presence of an intense band at $1739 \mathrm{~cm}^{-1}$ corresponding to the carbonyl stretching frequency of the PLA, not present in the unmodified CNC. Moreover, the signals of L-lactide, i.e. 1212 and $1296 \mathrm{~cm}^{-1}$, are absent, which provides the evidence that unreacted monomers are removed during washing.

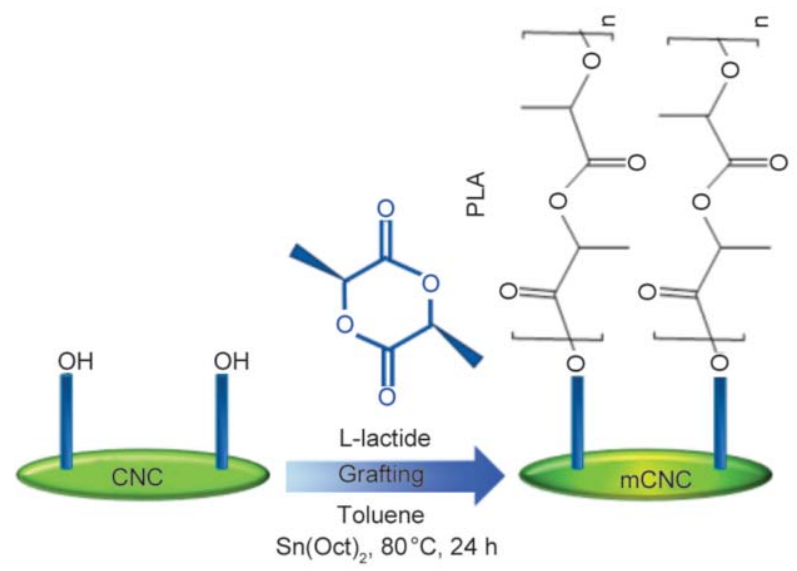

Figure 1. Scheme of PLA grafting on CNC surface via ring opening polymerization (ROP) technique.

\subsection{Nanocomposites preparation}

Nanocomposites of PLA with CNC and PLA with grafted $\mathrm{CNC}$ (mCNC) were prepared using a threestep solvent mixing technique. In the first step, PLA pellets were dissolved in 1,4 dioxane using a magnetic stirrer for $24 \mathrm{~h}$. At the same time, $1 \mathrm{wt} \% \mathrm{CNC}$ and $1 \mathrm{wt} \% \mathrm{mCNC}$ were separately dispersed in DMF using a magnetic stirrer for $2 \mathrm{~h}$ and ultrasonication for $5 \mathrm{~min}$. The dispersion of CNC was confirmed by flow birefringence. In step two, the dissolved PLA solution and the dispersed CNC suspensions were mixed and further stirred for $2 \mathrm{~h}$ and sonicated for $5 \mathrm{~min}$, resulting in a homogeneous dispersion of the CNCs in the PLA matrix. In the third step, this suspension of PLA with CNC or mCNC was used to prepare microspheres by dropping the suspension in liquid nitrogen (see Figure 2). The obtained microspheres were freeze-dried and kept in sealed plastic bags for further processing. PLA nanocomposites were prepared by adding $1 \mathrm{wt} \%$ of unmodified and modified CNC, henceforth referred to as PLA/CNC and PLA/mCNC, respectively.

\subsection{Extrusion-calendering of films}

From these microspheres, extruded calandered films of approximately of $0.1 \mathrm{~mm}$ thick were obtained. A single screw extruder (Lab Tech Engineering Company Ltd., Samutprakan, Thailand) with $L / D=30$ and $D=10 \mathrm{~mm}$ was used. The temperature profile ranged from $190^{\circ} \mathrm{C}$ (feed zone) to $200^{\circ} \mathrm{C}$ (die zone), and the screw speed was $40 \mathrm{rpm}$. During the calendering process, a hot stretching process was performed between two calendering rollers at a speed of 0.5 and $8 \mathrm{rpm}$, respectively, to obtain oriented films.

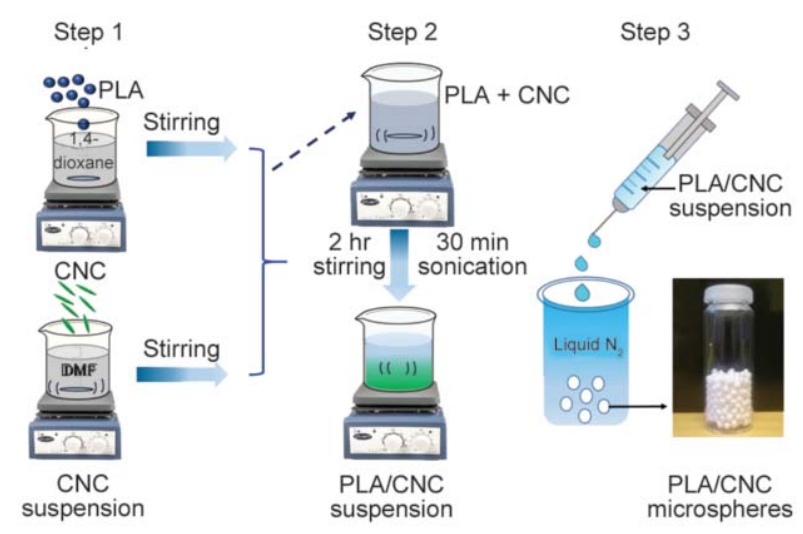

Figure 2. Schematic representation of PLA nanocomposites preparation by solvent mixing. 
In order to assure a better surface quality of the samples to be tested and to keep the orientation imparted in the CNC's during the extrusion-calendering, from the $0.1 \mathrm{~mm}$ thick films thicker ones $(0.3 \mathrm{~mm})$ were prepared, stacking 3 extruded foils (films), of approximately $120 \mathrm{~mm}$ in length, using a compression press moulding machine (IQAP LAP PL-15; IQAP Masterbatch group SL, Barcelona, Spain). The moulding temperature was set at $190^{\circ} \mathrm{C}$, and 15 bars of pressure was applied for $30 \mathrm{~s}$. After 3 minutes under pressure, the films were immediately cooled by immersing them in ice water.

To evaluate possible thermodegradation effects of this post-extrusion protocol, the viscosimetric molecular weight $\left(M_{\mathrm{v}}\right)$ was estimated through the determination of the intrinsic viscosity (IV) in chloroform at $30^{\circ} \mathrm{C}$, following the procedure described by Hakim et al. [16]. According to the results obtained, this processing causes a maximum loss of $8 \%$, and there are practically no effects of degradation.

\subsection{Tensile tests}

The mechanical properties of the nanocomposite films were tested on a Galdabini Sun 2500 universal tensile machine (Galdabini, Cardano al Campo, Italy) equipped with a $1 \mathrm{kN}$ load cell. The tensile tests were performed at room temperature with a crosshead speed of $2 \mathrm{~mm} \cdot \mathrm{min}^{-1}$. ISO 527-2 type 1BA dumbbell test specimens were extracted from the compression moulded films using a ZCP 020 manual cutting press (Zwick, Ulm, Germany). The actual displacement of the calibrated zone was measured with a video extensometer (OS-65D CCD, Minstron, Taipei, Taiwan) coupled to a Windows-based software (Messphysik, Fürstenfeld, Austria).

Before obtaining the tensile specimens, the films were subjected to a 'physical de-aging' (rejuvenating) thermal treatment, as by Cailloux et al. [17], to release internal stresses present in the samples and to avoid defects during cutting. The samples were kept at room temperature with a controlled relative humidity of $50 \%$ for one week before testing.

The engineering stress-strain curves for every sample were recorded, and tensile modulus $(E)$, tensile yield strength $\left(\sigma_{\mathrm{y}}\right)$, yield strain $\left(\varepsilon_{\mathrm{y}}\right)$ and strain at break $\left(\varepsilon_{\mathrm{b}}\right)$ were determined. The average values and corresponding standard deviation from five valid tests were calculated.

According to the first heating scan of DSC tests carried out on $5 \mathrm{mg}$ samples taken from these dumbbell specimens, the materials showed a crystallinity of less than $6 \%$ after the first heating scan, regardless of the addition of CNC (or $\mathrm{mCNC}$ ). Thus, they can be considered virtually amorphous, and with no crystallinity effect influencing the mechanical behaviour.

\subsection{Small punch test (SPT)}

Small punch tests were carried out on square samples of $10 \times 10 \mathrm{~mm}^{2}$ cut from the same heat-treated moulded plates as the tensile specimens. SPTs were performed using an experimental device designed and manufactured by the SIMUMECAMAT research group and mounted on a universal Instron testing machine equipped with a load cell of $5 \mathrm{kN}$. A punch diameter of $2.5 \mathrm{~mm}$, a hole in the lower die with a diameter of $4 \mathrm{~mm}$ (with $0.2 \mathrm{~mm}$ corner radius) and a displacement rate of $0.2 \mathrm{~mm} \cdot \mathrm{min}^{-1}$, were employed in all these tests. The punch displacement was measured using a COD extensometer attached between the upper and lower dies, as described by Rodríguez and coworkers $[12,18]$. The thickness of the specimens was measured using a precision micrometre as the average of six measurements. Ten specimens of each material were used in the SPT characterization.

\section{Results and discussions}

\subsection{Mechanical behaviour in the tensile test}

Representative engineering stress-strain curves of all the materials are compared in Figure 3, and the characteristic parameters are summarized in Table 1. Following the usual classification in polymeric materials [19] three types of behaviour (in terms of the stress-strain traces), can be observed. Firstly, 'Ductile'

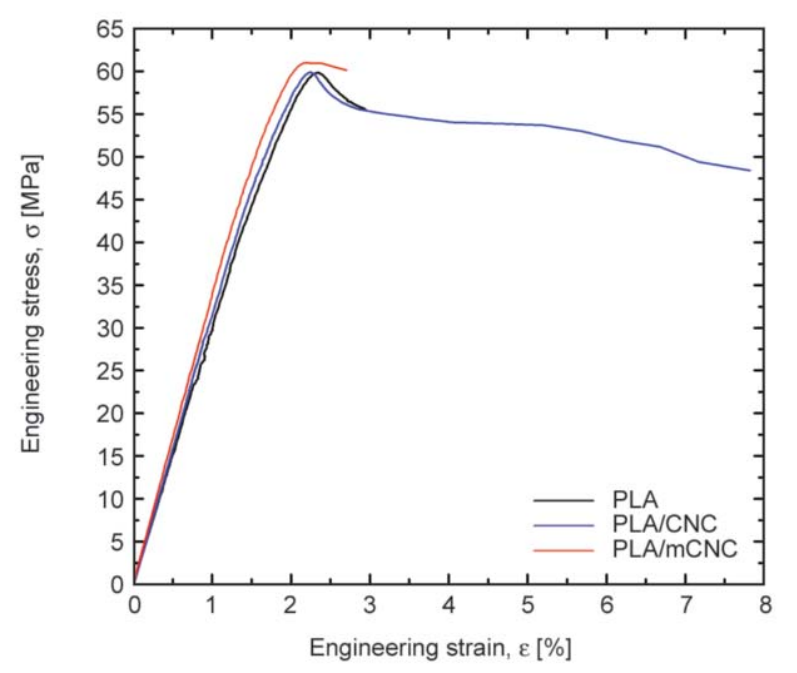

Figure 3. Engineering Stress-strain curves of PLA, PLA/ $\mathrm{CNC}$ and PLA/mCNC. 
Table 1. Tensile mechanical properties of PLA, PLA/CNC and PLA/mCNC.

\begin{tabular}{|ll|c|c|c|}
\hline \multirow{2}{*}{} & & \multicolumn{3}{|c|}{ Material } \\
\cline { 3 - 5 } & & PLA & PLA/CNC & PLA/mCNC \\
\hline$E$ & {$[\mathrm{GPa}]$} & $3.5 \pm 0.1$ & $3.6 \pm 0.1$ & $3.9 \pm 0.2$ \\
\hline$\sigma_{\mathrm{y}}$ & {$[\mathrm{MPa}]$} & $60 \pm 1$ & $60 \pm 2$ & $61 \pm 2$ \\
\hline$\varepsilon_{\mathrm{y}}$ & {$[\%]$} & $2.4 \pm 0.1$ & $2.2 \pm 0.1$ & $2.1 \pm 0.1$ \\
\hline$\varepsilon_{\mathrm{b}}$ & {$[\%]$} & $3.0 \pm 0.9$ & $8.0 \pm 1.0$ & $2.7 \pm 0.4$ \\
\hline
\end{tabular}

behaviour for PLA: after reaching the local maximum associated with the yield, there is a decrease in the engineering stress, which could be associated with a localized necking and subsequent rupture. Secondly, in the case of PLA/CNC, 'Ductile with cold drawing' behaviour which is associated with polymers is observed: after yielding, and necking appear, the engineering stress stabilizes, usually associated with a localized neck propagation, to then break. Finally, the addition of surface-modified $\mathrm{CNC}(\mathrm{mCNC})$ drastically changes these behaviour patterns, generating the typical curve of a brittle material: after reaching the local maximum the rupture occurs without apparent generation of a neck.

A visual inspection of tested samples revealed no necking around the broken zone but rather crazes which are a highly localized yield phenomenon, confined to a very small volume of material [20]. The drop in engineering stress observed in the curves of figure 3 is due to the decrease in the load-bearing section of the specimen as a consequence of the formation of crazes. These structures are shown as a whitening area by adjusting the angle of incidence of a light beam to the fracture surface (Figure 4). It seems that the modification of the CNC drastically decreases the number of crazes (see Figure 4c) as a consequence of the expected restriction of the matrix

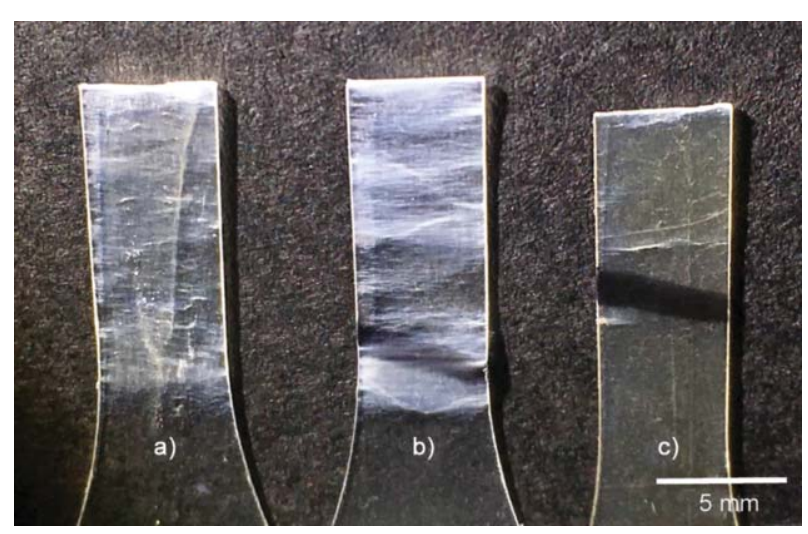

Figure 4. Photograph of broken zone from tensile specimens, (a) PLA, (b) PLA/CNC, and (c) PLA/mCNC. mobility thanks to the greater PLA-CNC interaction. The best matrix interaction of PLA-CNC has an equivalent effect of increasing the density of molecular entanglements; thus the critical hydrostatic stress for craze initiation will be greater than that required in neat PLA, as have been reported with others materials [21]. During the tensile test (uniaxial solicitation), this stress is not reached, and therefore significant numbers of crazes do not appear (Figure 4c). In the case of unmodified $\mathrm{CNC}$, a greater number of crazes are observed with respect to the PLA. The particles of $\mathrm{CNC}$ not adhered to the matrix may be acting as stress concentrators, thus promoting a greater number of crazes with a smaller size compared to neat PLA. This increases the volume of plastic deformation involved in the deformation process, providing a slight gain in ductility to the system [17, 20]. As can be seen in Table 1 there is an increase of $167 \%$ of the elongation at break $\left(\varepsilon_{\mathrm{b}}\right)$ with respect to neat PLA. Also, it can be observed that the addition of $\mathrm{mCNC}$ causes an increase of $11 \%$ in the elastic modulus of the PLA, with no apparent change when the $\mathrm{CNC}$ is unmodified. This may be related to a better matrix-CNC interaction promoted by the grafted PLA on the surface of the CNC.

Figure 5 shows the micrographs of the surfaces generated after a special sharp-notched dumbbell tensile sample tested at $2 \mathrm{~mm} \cdot \mathrm{min}^{-1}$. This test was performed to view the situation without excessive tearing of the surface. It is observed that the addition of $\mathrm{mCNC}$ results in a greater number of cavitations of smaller size (Figure 5b) compared to those of unmodified CNC (Figure 5a). This can be attributed to the better dispersion and distribution of the CNC with PLA chain grafted on its surface. This better dispersion, together with the improved interaction with the PLA matrix, increases the reinforcement efficiency of $\mathrm{mCNC}$.

\subsection{Small punch test (SPT) results}

It should be emphasized that in SPT a biaxial loading mode is applied. Thus, the deformation process of the sample may vary compared to the uniaxial loading mode (tensile test).

During the SPT all specimens generated a cap before the final break, typical of a ductile failure of the structure. However, two different types of breaks were observed, which have been classified as 'stable' and 'unstable'. These two different break behaviours can be detected through both the load (normalized by 


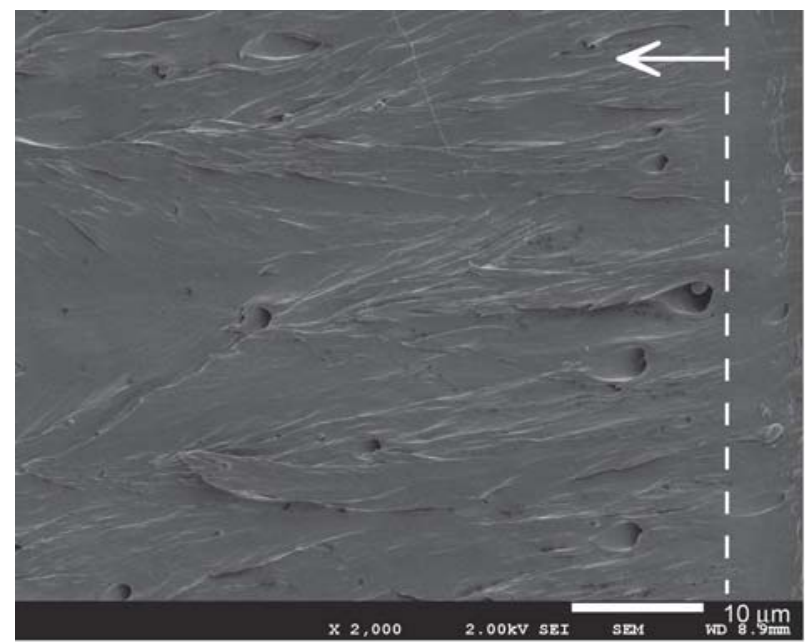

a)

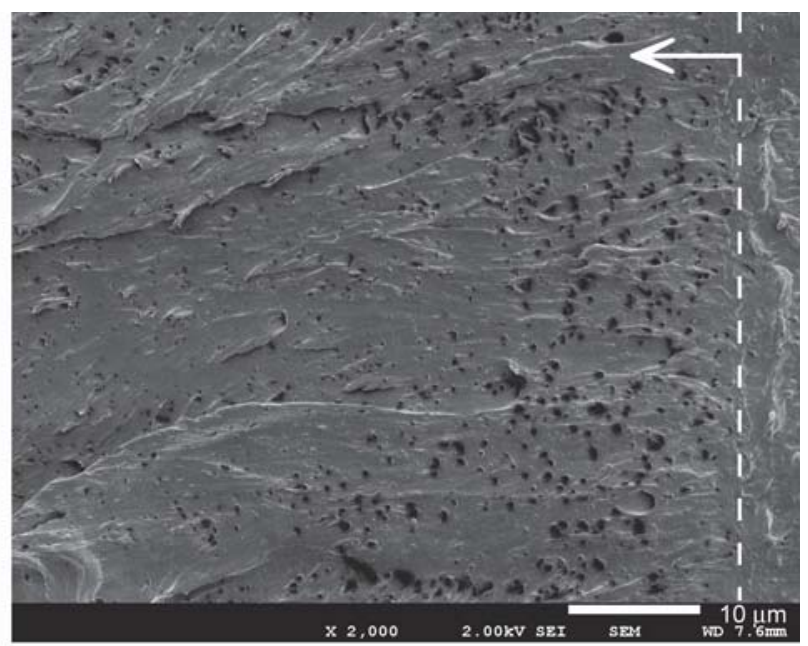

b)

Figure 5. SEM micrographs of fracture surfaces taken from sharp-notched dumbbell tensile tests of: a) PLA/CNC and b) PLA/mCNC. Dashed line indicates the sharp-notch edge. Crack growth direction pointed with arrows.

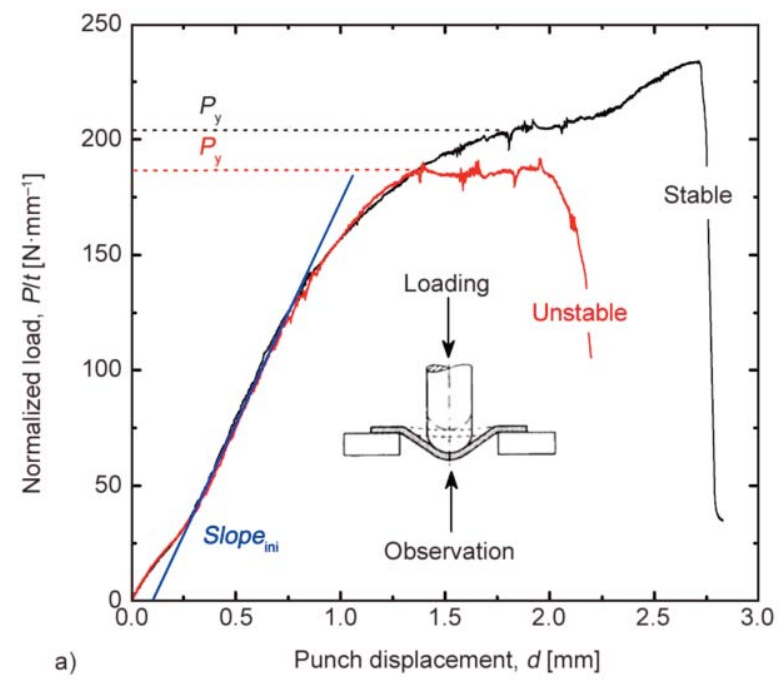

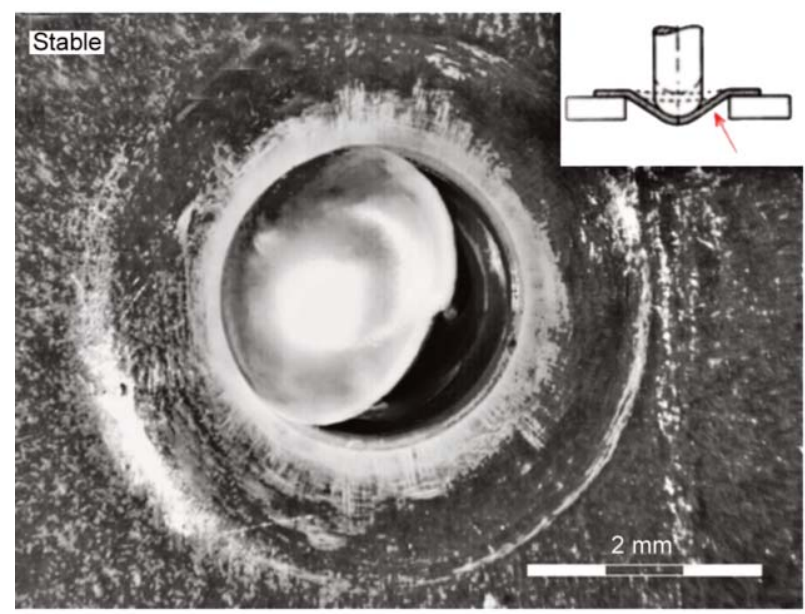

b)

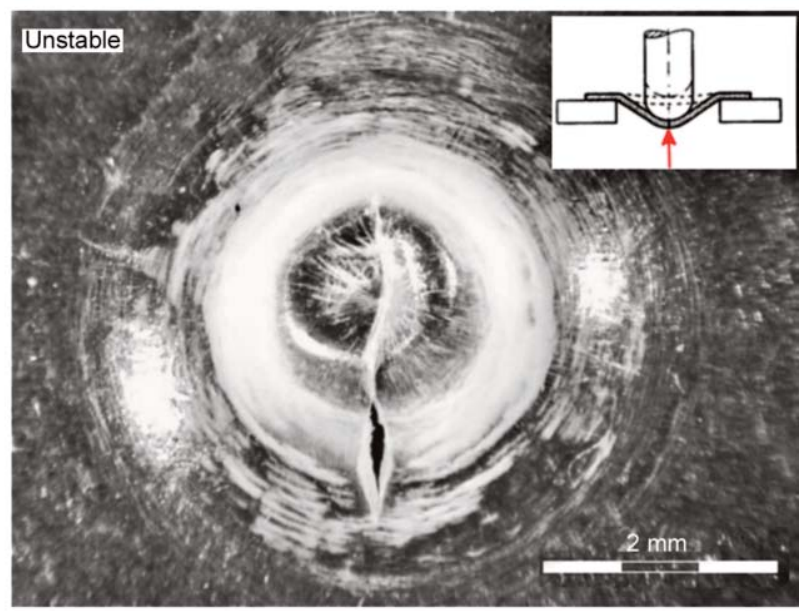

c)

Figure 6. a) Representative thickness normalized load - punch displacement curves obtained for unstable and stable-ductile behaviour in PLA/mCNC. Inset: Simplified scheme of the loading solicitation mode during SPT. b) and c) optical micrographs of the tested samples with stable-ductile behaviour in PLA and unstable-ductile behaviour in $\mathrm{PLA} / \mathrm{mCNC}$, respectively. In upper right corner it is pointed with the arrow the location of the crack. 
thickness) vs punch displacement curves (Figure 6a) and the appearance of the failure region (Figures $6 \mathrm{~b}$ and $6 \mathrm{c}$ ).

Figure 6a shows a schematic of the specimen during loading and the observation direction, by optical microscopy, after being tested. The traces of the normalized load-punch displacement curves in the initial zone, associated with elastic deformation, are similar for both types of failure. Differences occur once the plastic collapse stress is exceeded. In the ductile-stable behaviour, typical of the PLA and PLA/CNC, a decrease of the curve slope is observed before a new increase. This behaviour can be attributed to the combination of strain hardening of the material and friction between the specimen and the punch during its advance. In the case of unstable-failure, typical of $\mathrm{PLA} / \mathrm{mCNC}$, once a certain load level is reached, there is a sudden load drop followed by a plateau which is associated with the crack propagation.

In the case of the stable-ductile failure, the crack is located in the wall of the cap (Figure 6b) while those with unstable failure the crack is generated at the pole of the cap (Figure 6c). These facts are in agreement with the results obtained from a preliminary numerical simulation of SPT on an Ethylene Vinyl Alcohol copolymer, EVOH, (Figure 7) which has ductile behaviour in tensile tests [12]. In this case, an ideal elasto-plastic model with the EVOH tensile parameters $\left(E\right.$ and $\left.\sigma_{\mathrm{y}}\right)$ was used. The location of the greatest stress was observed at the maximum necking region (yellow circle), where the crack appears in the materials that suffer stable-ductile failure.

However, when the capacity for plastic deformation of the material is restricted, the crack appears prematurely on the face opposite the contact with the punch (under a tensile field) and located at the pole of the cap, which is the region subjected to maximum stress values. The appearance of this new free surface limits the capacity of stress transfer in the system and restricts the propagation of the neck in the wall of the cap. Consequently, the curves do not show the zone associated with the hardening.

It should be noted that depending on the type of material, the proportion of stable-ductile to unstableductile failures varies. The addition of $\mathrm{CNC}$ in the PLA does not modify the type of failure, being $100 \%$ stable-ductile in both materials (PLA and PLA/CNC). However, after modifying the surface of the CNC, unstable-ductile failure becomes the typical mode of failure, present in more than $80 \%$ of the tested specimens. This observation could be associated with the capacity of plastic deformation of each material. The adhesion between $\mathrm{mCNC}$ and the matrix restricts the already limited deformation ability of PLA.

The different patterns of craze growth developed in each type of failure mode are shown in Figures $6 b$

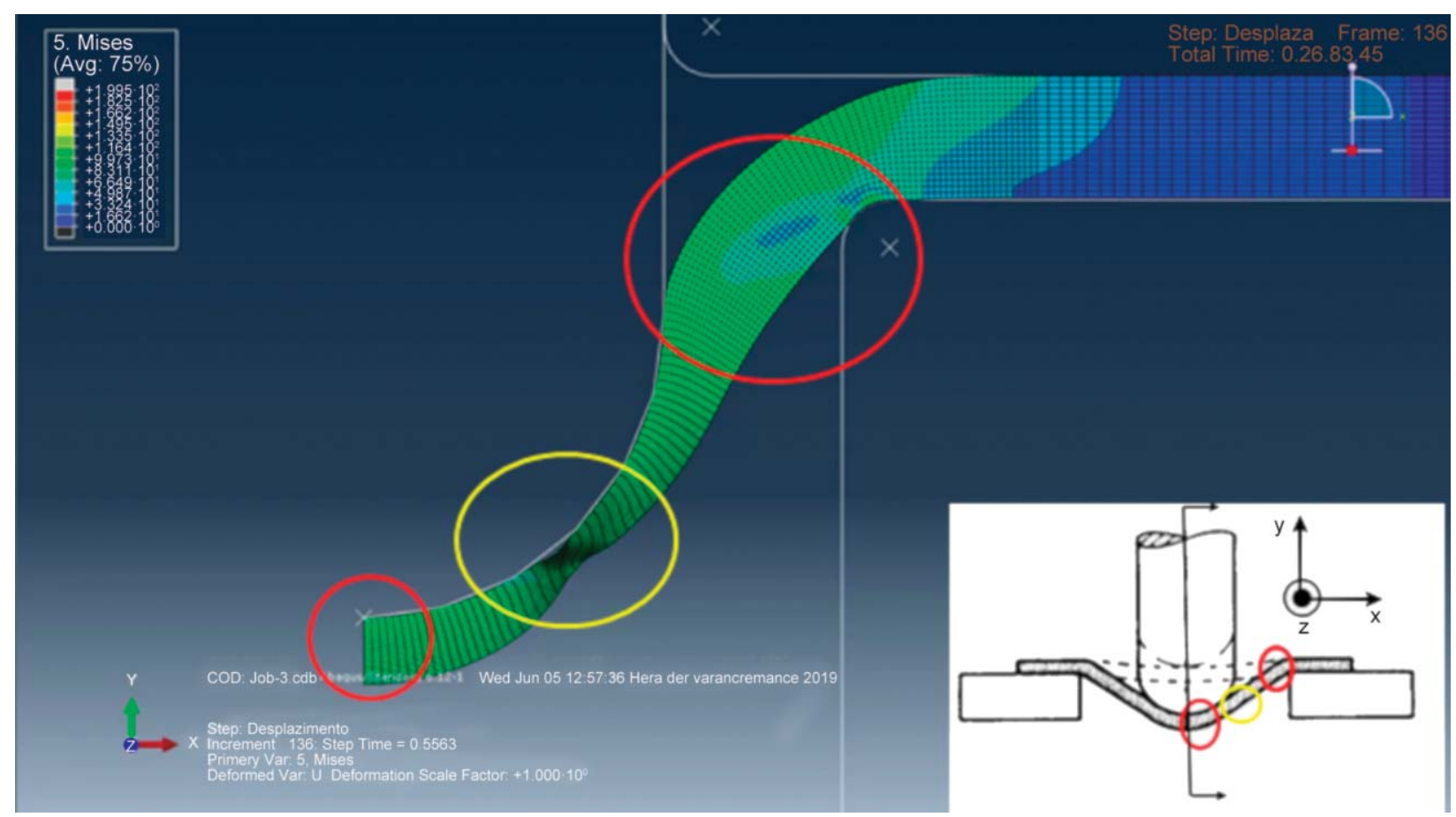

Figure 7. Image taken from a preliminary numerical simulation of the SPT test in EVOH, as an example of ductile behaviour in tensile test. Inset: Simplified scheme of the loading geometry and regions taken for monitoring the stress field involved during SPT. 
and $6 \mathrm{c}$. In PLA and PLA/CNC the crazes are mostly oriented in the radial direction (see Figure $6 \mathrm{~b}$ corresponding to the PLA), concentrated in the necking area of Figure 7 (yellow circle). In the case of PLA/ $\mathrm{mCNC}$ (Figure $6 \mathrm{c}$ ) there is an increase in the number of crazes, and different orientation: tangential to the punch. This rise in the number of crazes increases the chances of unstable failure.

During SPT the generation of localized necking can act as a stress relief mechanism. In systems where the necking is restricted (PLA/mCNC), there is no such stress relief, so that the stress state in the red circle regions of Figure 7 can reach the critical hydrostatic stress to initiate crazes.

As it is well known, crazes appear and grow perpendicular to the resulting tensile component of the local stress field $[17,20]$. In the case of PLA and PLA/ $\mathrm{CNC}$, this component seems to be oriented tangentially to the punch, perhaps induced by the local deformation constraint in that direction. In the case of $\mathrm{PLA} / \mathrm{mCNC}$, the tensile resultant is located radially, coinciding with the face of the sheet that is subjected to traction.

Once normalized by thickness, the obtained values of Slope $e_{\text {ini }}$ and $P_{\mathrm{y}}\left(S l o p e_{\text {ini }} / t\right.$ and $\left.P \mathrm{y} / t^{2}\right)$ are summarized in Table 2 . The value of $P_{\mathrm{y}}$ has been defined differently for each type of breaking behaviour, i.e. stable-ductile and unstable-ductile. In the case of unstable failure, $P_{\mathrm{y}}$ coincides with the first registered load maximum. In the case of stable ductile behaviour, $P_{\mathrm{y}}$ is taken as the load value, after the elastic

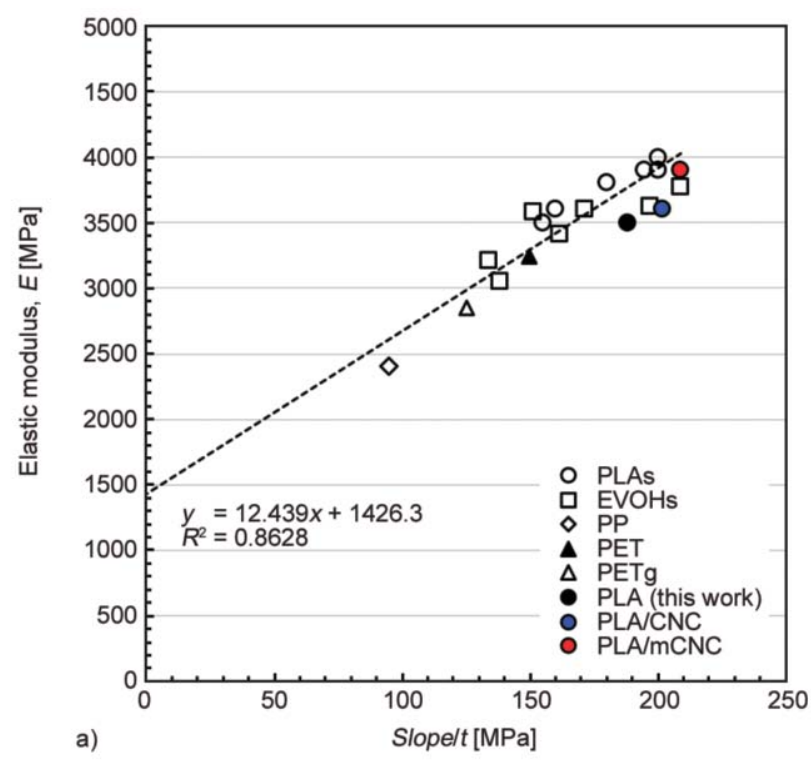

Table 2. SPT parameters of PLA, PLA/CNC and $\mathrm{PLA} / \mathrm{mCNC}$.

\begin{tabular}{|ll|c|c|l|}
\hline \multirow{2}{*}{\multicolumn{2}{|c|}{ Parameter }} & \multicolumn{3}{c|}{ Material } \\
\cline { 3 - 6 } & & PLA & CNC & mCNC \\
\hline Slope $_{\text {ini }} / t$ & {$[\mathrm{MPa}]$} & $188 \pm 7$ & $202 \pm 3$ & $209 \pm 9$ \\
\hline$P_{\mathrm{y}} / t_{2}$ & {$[\mathrm{MPa}]$} & $679 \pm 74$ & $712 \pm 45$ & $671 \pm 69$ \\
\hline$E$ (Predicted) & {$[\mathrm{GPa}]^{*}$} & $3.6 \pm 0.2$ & $3.7 \pm 0.3$ & $3.9 \pm 0.3$ \\
\hline
\end{tabular}

${ }^{*}$ From Equation (1) and fitting values of Figure 8a.

region, from which the first derivative of the loaddisplacement trace becomes constant again. It must be remembered that independently of the type of failure, the process involved is shear yielding, so this $P_{\mathrm{y}}$ value is related to the initiation of this process.

Figures $8 \mathrm{a}$ and $8 \mathrm{~b}$ show these SPT parameters (Slope $e_{\text {ini }} / t$ and $P_{\mathrm{y}} / t^{2}$ ) versus the corresponding experimental tensile properties $\left(E\right.$ and $\left.\sigma_{\mathrm{y}}\right)$. These graphs also include the characteristic values of other polymeric materials reported in previous works [12] and their linear fitting coefficient by way of comparison. As can be seen in Figure 8a, the values obtained for $S_{\text {Slope }}$ ini $_{1} /$ follow the expected trend and agree with the values of elastic modulus obtained in the tensile tests. Thus, these results corroborate that SPTs can predict the elastic modulus of polymeric materials in biaxial loading by means of Equation 1. Using the coefficients of the linear regression fit of previous work [12], the predicted values of $E$ (Table 2) are in good agreement with the experimental ones reported in Table 1.

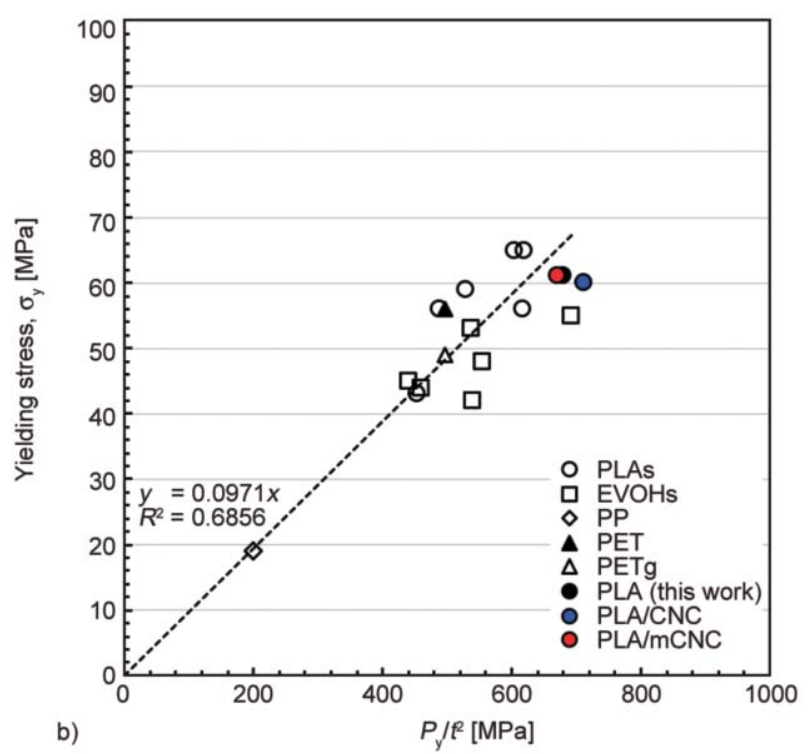

Figure 8. Graphical correlation between SPT and tensile parameters: a) $S l o p e_{\text {ini }} / t v s . E$ and b) $P_{\mathrm{y}} / t^{2} v s$. $\sigma_{\mathrm{y}}$. Filled circles correspond to materials of this work (PLA in black, PLA/CNC in blue and PLA/mCNC in red). Other polymeric materials data are taken and adapted from [12]. 
However, the $P_{\mathrm{y}} / t^{2}$ values do not follow any trend. Furthermore, the correlation shown in Figure 8b, corresponding to Equation 2, shows a poor linear regression fit. It must be taken into account that in this region of the mechanical behavior the viscoelastic effects take on importance. Not all polymeric materials have the same sensitivity with the deformation speed in this region.

Therefore, it may be impossible to obtain a universal $\beta$ coefficient for the adjustment of different polymeric materials tested under the same conditions of displacement speeds of jaws and/or punch, since it is not guaranteed that the strain rates are the same between them. This aspect is not so critical in the elastic region of the material, where the consequences of the viscoelastic effects are minimized.

By the other side, it is necessary to clearly define how parameter $P_{\mathrm{y}}$ is determined in polymeric materials and its relationship with $\sigma_{\mathrm{y}}$. Perhaps the parameter should not be $P_{\mathrm{y}} / t^{2}$ but rather one which considers the punch displacement at the yield moment $\left(d_{\mathrm{y}}\right)$, $P_{\mathrm{y}} /\left(t \cdot d_{\mathrm{y}}\right)$, similar to that used to estimate the ultimate tensile strength in metals [18]. An extensive revision of the correlations in metallic materials has recently been proposed, as these are developed from a specified set of materials and testing conditions [22, 23].

\section{Conclusions}

Under uniaxial loading (tensile tests), the addition of CNC promotes multiple crazing in the PLA matrix that increases its ductility. The crazing process is reduced with the surface modification of $\mathrm{CNC}$, which demonstrates better adhesion of the nanoparticle to the matrix. Under biaxial loading (SPT), depending on the type of material, the proportion of stable-ductile to unstable-ductile failures varies. The addition of CNC in the PLA does not modify the type of failure, being $100 \%$ stable-ductile in both materials (neat PLA and PLA/CNC). Adding modified $\mathrm{CNC}$ ( $\mathrm{mCNC}$ ), unstable-ductile failure becomes the typical mode of failure. Hence, the elastic modulus and embrittlement of PLA/mCNC increase slightly.

The applicability of the small punch test (SPT) to predict the tensile modulus, $E$, of nanocomposites of PLA and CNC has been shown. It is necessary to clearly define the correct way to calculate the SPT yield load, $P_{\mathrm{y}}$, in polymeric materials as well as the correct SPT parameter that relates it with $\sigma_{\mathrm{y}}$.

\section{Acknowledgements}

The authors would like to acknowledge the European Union for its financial support of Shikha Singh for the Joint European Doctoral Programme in Advanced Material Science and Engineering (DocMASE) and the Spanish Ministry of Economy and Competitiveness for the MAT2016-80045R project.

\section{References}

[1] Auras R. A., Lim L-T., Selke S. E. M., Tsuji H. T.: Poly(lactic acid): Synthesis, structures, properties, processing, and applications. Wiley, Hobodoken (2010). https://doi.org/10.1002/9780470649848

[2] Velazquez-Infante J. C., Gamez-Perez J., FrancoUrquiza E. A., Santana O. O., Carrasco F., Maspoch M. L.: Effect of the unidirectional drawing on the thermal and mechanical properties of PLA films with different L-isomer content. Journal of Applied Polymer Science, 127, 2661-2669 (2013). https://doi.org/10.1002/app.37546

[3] Bondeson D., Syre P., Niska K. O.: All cellulose nanocomposites produced by extrusion. Journal of Biobased Materials and Bioenergy, 1, 367-371 (2007). https://doi.org/10.1166/jbmb.2007.011

[4] Gray D. G.: Transcrystallization of polypropylene at cellulose nanocrystal surfaces. Cellulose, 15, 297-301 (2008).

https://doi.org/10.1007/s10570-007-9176-2

[5] Tanpichai S., Oksman K.: Crosslinked poly(vinyl alcohol) composite films with cellulose nanocrystals: Mechanical and thermal properties. Journal of Applied Polymer Science, 135, 45710/1-45710/11 (2018).

https://doi.org/10.1002/app.45710

[6] Mathew A. P., Oksman K., Sain M.: The effect of morphology and chemical characteristics of cellulose reinforcements on the crystallinity of polylactic acid. Journal of Applied Polymer Science, 101, 300-310 (2006). https://doi.org/10.1002/app.23346

[7] Yu H-Y., Zhang H., Song M-L., Zhou Y., Yao J., Ni Q-Q.: From cellulose nanospheres, nanorods to nanofibers: Various aspect ratio induced nucleation/reinforcing effects on polylactic acid for robust-barrier food packaging. ACS Applied Materials and Interfaces, 9, 43920-43938 (2017).

https://doi.org/10.1021/acsami.7b09102

[8] Oksman K., Aitomäki Y., Mathew A. P., Siqueira G., Zhou Q., Butylina S., Tanpichai S., Zhou X., Hooshmand S.: Review of the recent developments in cellulose nanocomposite processing. Composites Part A: Applied Science and Manufacturing, 83, 2-18 (2016). https://doi.org/10.1016/j.compositesa.2015.10.041

[9] Mujica-Garcia A., Hooshmand S., Skrifvars M., Kenny J. M., Oksman K., Peponi L.: Poly(lactic acid) meltspun fibers reinforced with functionalized cellulose nanocrystals. RSC Advances, 6, 9221-9231 (2016). https://oi.org/10.1039/C5RA22818B 
[10] Giddings V. L., Kurtz S. M., Jewett C. W., Foulds J. R., Edidin A. A.: A small punch test technique for characterizing the elastic modulus and fracture behavior of PMMA bone cement used in total joint replacement. Biomaterials, 22, 1875-1881 (2001).

https://doi.org/10.1016/S0142-9612(00)00372-0

[11] Jaekel D. J., MacDonald D. W., Kurtz S. M.: Characterization of PEEK biomaterials using the small punch test. Journal of the Mechanical Behaviour of Biomedical Materials, 4, 1275-1282 (2011).

https://doi.org/10.1016/j.jmbbm.2011.04.014

[12] Rodríguez C., Cuesta I. I., Maspoch M. L., Belzunce F. J.: Application of the miniature small punch test for the mechanical characterization of polymer materials. Theoretical Applied Fracture Mechanics, 86, 78-83 (2016). https://doi.org/10.1016/j.tafmec.2016.10.001

[13] Rodríguez C., Arencón D., Belzunce J., Maspoch M. L.: Small punch test on the analysis of fracture behaviour of PLA-nanocomposite films. Polymer Testing, 33, 21 29 (2014).

https://doi.org/10.1016/j.polymertesting.2013.10.013

[14] Maspoch M. L., Santana O. O., Cailloux J., FrancoUrquiza E., Rodriguez C., Belzunce J., Martínez A. B.: Ductile-brittle transition behaviour of PLA/o-MMT films during the physical aging process. Express Polymer Letters, 9, 185-195 (2015).

https://doi.org/10.3144/expresspolymlett.2015.20

[15] Cailloux J., Santana O. O., Franco-Urquiza E., Bou J. J., Carrasco F., Gámez-Pérez J., Maspoch M. L.: Sheets of branched poly(lactic acid) obtained by one step reactive extrusion calendering process: Melt rheology analysis. Express Polymer Letters, 7, 304-318 (2012). https://doi.org/10.3144/expresspolymlett.2013.27

[16] Hakim R. H., Cailloux J., Santana O. O., Bou J., Sánchez-Soto M., Odent J., Raquez J. M., Dubois P., Carrasco F., Maspoch M. L.: PLA/SiO2 composites: Influence of the filler modifications on the morphology, crystallization behavior, and mechanical properties. Journal of Applied Polymer Science, 134, 45367/145367/12 (2017).

https://doi.org/10.1002/app.45367
[17] Cailloux J., Santana O. O., Franco-Urquiza E., Bou J. J., Carrasco F., Maspoch M. L.: Sheets of branched poly (lactic acid) obtained by one-step reactive extrusioncalendering process: Physical aging and fracture behavior. Journal of Materials Science, 49, 4093-4107 (2014). https://doi.org/10.1007/s10853-014-8101-y

[18] García T. E., Rodríguez C., Belzunce F. J., Suárez C.: Estimation of the mechanical properties of metallic materials by means of the small punch test. Journal of Alloys and Compounds, 582, 708-717 (2014). https://doi.org/10.1016/j.jallcom.2013.08.009

[19] Ward I. M., Sweeney J.: The mechanical properties of polymers: General considerations. in 'Mechanical properties of solid polymers: Third edition' (eds.: Ward I. M., Sweeney J.) Wiley, Chichester, 19-21 (2013). https://doi.org/10.1002/9781119967125.ch2

[20] Kinloch A. J., Young R. J.: Crazing. in 'Fracture behaviour of polymers' (eds.: Kinloch A. J., Young R. J.) Springer, Dordrecht, 147-181 (1995). https://doi.org/10.1007/978-94-017-1594-2 5

[21] Donald A. M.: Crazing. in 'The physics of glassy polymers' (eds.: Haward R. N., Young R. J.) Springer, Dordrecht, 295-339 (1997). https://doi.org/10.1007/978-94-011-5850-3_6

[22] Bruchhausen M., Austin T., Holmström S., Altstadt E., Dymacek P., Jeffs S., Lancaster R., Lacalle R., Matocha K., Petzová J.: European standard on small punch testing of metallic materials. in 'ASME 2017 Pressure Vessels and Piping Conference, Waikoloa, USA' PVP201765396/1-PVP2017-65396/14 (2018). https://doi.org/10.1115/PVP2017-65396

[23] Arunkumar S.: Overview of small punch test. Metals and Materials International, 26, 4545/1-4545/20 (2020). https://doi.org/10.1007/s12540-019-00454-5 